\title{
O pato, a morte e a tulipa - Leitura e discussão de um livro ilustrado desafiador com alunos dos anos iniciais
}

\section{Duck, Death and the Tulip - Reading and discussing a challenging picture book with elementary school children}

\author{
Edgar Roberto Kirchof* \\ Rosa Maria Hessel Silveira**
}

\begin{abstract}
RESUMO
Este artigo tem como objetivo analisar a recepção e a discussão do livro ilustrado $O$ pato, a morte e a tulipa, de Wolf Erlbruch, com base em um trabalho de leitura realizado com duas turmas de $4^{\circ}$ ano de ensino fundamental em escolas públicas de Porto Alegre-RS. A partir da análise de elementos estruturais da obra - principalmente a relação entre texto verbal e imagético - e da temática da morte na literatura para crianças, o artigo apresenta os resultados de uma análise sobre como os leitores infantis interagiram com as mensagens do texto de Erlbruch, negociando sentidos a partir de seus próprios repertórios culturais e cognitivos. Os principais autores que embasam as discussões sobre a morte e a literatura infantil são Fanuel H. Díaz, M. A. Katrin Hesse, Norbert Elias, Jan Reinhardt, Simone Weber, Teresa Colomer, ao passo que as análises sobre as múltiplas respostas das crianças à leitura do livro inspiram-se nos estudos sobre conversa literária, de Aidan Chambers.
\end{abstract}

Palavras-chave: Literatura para crianças. O pato, a morte e a tulipa. Morte. Leitura literária em sala de aula.

* Universidade Luterana do Brasil. Curso de Letras e Programa de Pós-Graduação em Educação. Canoas, Rio Grande do Sul, Brasil. E-mail: ekirchof@hotmail.com. https://orcid org/0000-0002-1072-2547.

*** Universidade Federal do Rio Grande do Sul. Programa de Pós-Graduação em Educação. Porto Alegre, Rio Grande do Sul, Brasil. E-mail: rosamhs@gmail.com. https://orcid.org/00000001-5797-6627. 


\begin{abstract}
In this article, we analyze the reception of the picture book Duck, death and the tulip, by the German artist Wolf Erlbruch, based on reading practices conducted in two 4th grade classes of elementary public schools in Porto Alegre (state of Rio Grande do Sul, Brazil). Our analyzes focus on the ways in which children readers interact with Erlbruch's literary text and make sense of its messages based on their own cultural and cognitive repertoires. The article also analyzes the book's structural elements, especially the synergy between verbal and pictorial language as well as the way Erlbruch portrays the issue of death. Our discussions about death and literature for children draw on the studies of among others Fanuel H. Díaz, Norbert Elias, Jan Reinhardt, Simone Weber, Teresa Colomer, whereas the analyzes of the children's multiple responses to the book are inspired in the studies of literary conversation by Aidan Chambers.
\end{abstract}

Keywords: Literature for children. Duck, death and the tulip. Death. Literary reading in the classroom.

\title{
Palavras introdutórias
}

Numa palestra recente de um dos autores deste artigo, em que se relatava e discutia a leitura de uma obra que abordava um tema delicado, realizada com alunos dos anos iniciais, a primeira pergunta da plateia de professoras e professores, após o término da fala, foi a seguinte: "Por que vocês escolheram este livro tão triste para trabalhar?" Esta é uma questão sempre revisitada quando se abordam as relações entre livros literários e infância e é motivada pelas nossas representações de infância - vista como idade da alegria, da despreocupação, do descompromisso, a ser protegida e preservada das "tristezas da vida". Qual o sentido, por exemplo, de ler um livro que tematiza a morte, com crianças, e conversar sobre ele? Esta é apenas uma das dimensões do presente artigo, em que um tema delicado, embora universal e perene - a morte -, é abordado com base na leitura de uma obra literária desafiadora e original: $O$ pato, a morte $e$ a tulipa, de Wolf Erlbruch.

Integrando os estudos e análises realizadas no contexto da pesquisa intitulada Percursos e Representações da Infância em Livros para Crianças - Um Estudo de Obras e de Leituras ${ }^{1}$, cujo objetivo geral é analisar dimensões da

1 Pesquisa realizada com apoio do CNPq, através de Auxílio Pesquisa, bolsas PQ e de Iniciação Científica. 
compreensão leitora de obras literárias por alunos de escolas públicas que frequentam anos iniciais, o artigo se beneficia de uma das frentes metodológicas do projeto. Para atender ao objetivo enunciado, realizam-se, em salas de aula, sessões de leitura compartilhada de obras anteriormente escolhidas, sendo que cada dupla de alunos tem um exemplar à sua disposição. Seguem-se, à leitura, momentos de discussão da obra, assim como a realização de atividades diversificadas - escritas, plásticas, encenações - motivadas pela obra trabalhada, no que diz respeito ora a sua temática, ora a aspectos de cunho mais formal. Para as atividades, um objetivo sempre buscado é desafiar os leitores a fazerem conexões entre o universo construído na obra e as experiências de vida próprias de cada um.

Uma inspiração teórica constante do grupo de pesquisa vem das ideias de Chambers $(2007,2008)$, que tem se debruçado a esquadrinhar a relevância das conversas sobre leituras literárias. Partindo de reflexões feitas sobre experiências com grupos de diferentes características (etárias, geográficas, sociais), esse autor defende a relevância da partilha de percepções de leitura em conversas mediadas, para o aprofundamento de diferentes interpretações possibilitadas pelos livros. "A literatura nos oferece imagens com as quais pensar a vida", afirma Chambers (2008, p.23). Além disso, em uma de suas obras mais traduzidas, Dime (2007), o autor enfatiza a importância de se "falar sobre as leituras", fugindo ao acento pedagógico tradicional de chegar a um consenso sobre o significado correto da obra, e respeitando o entendimento de que "Hablar sobre los libros (...) y hablar sobre lo que pensamos y sentimos mientras leemos está em El corazón de toda la enseñanza de la literatura" (CHAMBERS, 2008, p. 176). Também importa sua concepção de que, embora permaneça como "líder" da discussão, o professor deve se comportar como um leitor a mais e deve "ayudar a cada persona a descobrir honestamente el livro que há leído" (CHAMBERS, 2008, p. 177).

É dentro desse quadro mais amplo que se situa o presente artigo, cujo objetivo é apresentar os resultados de um estudo realizado a partir de sessões de leitura com crianças de duas escolas públicas, de redes distintas, na cidade de Porto Alegre, Rio Grande do Sul. Para que seja possível um maior aprofundamento, dentre os vários títulos escolhidos e trabalhados nas escolas pelo grupo de pesquisa, traremos, neste texto, apenas o trabalho realizado com a obra $O$ pato, a morte e a tulipa, do autor alemão Wolf Erlbruch. Organizamos o artigo da seguinte forma: depois desta introdução, será apresentada uma abordagem sucinta da temática da morte na literatura para crianças, seguida por uma breve análise da obra de Erlbruch. Então, traremos algumas questões abordadas pelas crianças na conversa mediada sobre o livro, e o artigo se encerra com algumas considerações finais. 


\section{A morte nos livros para crianças}

Embora representada e abordada de maneiras muito diversas, a temática da morte sempre esteve presente nos livros produzidos para crianças, desde o século XVIII até os dias de hoje. Nos contos de fada - um dos gêneros mais antigos e populares para crianças -, por exemplo, a morte é abordada de forma recorrente, e a popularidade dessas histórias fez com que vários de seus esquemas narrativos fossem assimilados e adaptados ao longo dos anos, sendo possível encontrar alguns deles mesmo em livros contemporâneos. Em sua ampla pesquisa sobre o assunto, M. A. Katrin Hesse (2015) identifica algumas dessas fórmulas e seus ensinamentos correspondentes, tais como a morte de um vilão malvado no final da história significando punição por mau comportamento, a morte de um herói ou de um mártir sugerindo o sacrifício de um santo ou, ainda, a morte de uma criança ou adulto que sofre para realizar a passagem na direção do paraíso ou da vida eterna.

Por outro lado, desde o século XIX, o fortalecimento da visão burguesa da infância como uma fase diferenciada em relação aos adultos - frágil, que requer cuidados e precisa ser protegida, serviu como inspiração para representações mais amenas e, frequentemente, romantizadas da morte em livros infantis (REINHARDT; WEBER, 2008), as quais passaram a predominar já desde o final do século XIX até o século XX; em muitos casos, inclusive, a morte se transformou em um tabu para o público infantil, por se tratar de um tema supostamente difícil, com o qual se acreditava que as crianças não estariam preparadas para lidar.

Por outro lado, nos últimos anos, ao menos no mercado editorial, tal concepção vem se modificando radicalmente, pois a morte parece ter se transformado em um tema não apenas aceitável, mas inclusive recomendável para ser abordado em livros infantis. No contexto alemão, por exemplo, Hesse (2015, p. 121) afirma que, até a década de 1980 , a morte era tratada como um tabu pelo mercado editorial, o que mudou radicalmente a partir da década de 1990, quando, ao contrário do que ocorria até então, a morte acabou se transformando em um tema da moda em livros para crianças. Também no contexto espanhol, com base na análise de 150 obras consideradas as melhores publicadas na Espanha entre 1977 e 1990, Teresa Colomer (2003, p. 277) constatou a progressiva "incorporação de temas excluídos até agora dos livros infantis por sua inadequação à etapa da infância", [...]"por sua dureza ou complexidade moral", registrando, entre esses temas, a questão da morte. 
Nos livros mais recentes que passaram a abordar a temática, como observou Díaz (1996), há o predomínio de um tópico específico: a abordagem da morte ligada à perda dos avós ou de pessoas mais velhas por parte de um protagonista infantil. Em seus termos, "enquanto no século passado e no início deste [séc. $\mathrm{XX}]$ não se fazia discriminação entre as personagens de ficção vítimas desta experiência, modernamente é mais frequente encontrar livros que abordam o desenvolvimento do tema a partir dos anciãos" (DÍAZ, 1996, p.8). Além disso, os livros que abordam a morte de avós estão imbuídos da intenção de trazer algum tipo de consolo para a criança que sofre com a perda; no que diz respeito à maneira como o consolo é apresentado, embora ainda ocorra, em alguns casos, a repetição de fórmulas típicas dos contos de fada tradicionais. Reinhardt e Weber (2008) afirmam que grande parte desses livros recentes tendem para soluções mais secularizadas, desprovidas de explicações metafísicas ou religiosas: nessas narrativas, "o morrer e a morte são vistos como pontos finais ou limites naturais de uma vida pensada apenas como imanente" (REINHARDT; WEBER, 2008, p. 56) ou, nos termos de Díaz, como "um fenômeno natural, como uma etapa a mais da existência a que chegaremos. [...] É a inevitável consequência do desgaste do corpo quando envelhece". (DÍAZ, 1996, p.8). O livro Servus Opa, sagteichleise [Eu disse baixinho: Olá, Vovô], publicado em 1977 por Elfie Donnellye Christian B. Sadil, é considerado, por Reinhardt e Weber, um marco quanto a essa perspectiva no contexto germânico, tendo inaugurado um tipo de consolo que vem se repetindo em vários outros livros mais recentes do gênero: "Ninguém está realmente morto enquanto houver alguém que pense nessa pessoa" (REINHARDT; WEBER, 2008, p. 57).

Em um estudo realizado sobre essa temática no contexto brasileiro, Silveira e Dalla Zen (2013) analisaram um conjunto de 20 obras de autores brasileiros, publicadas a partir dos anos 2000 , pertencentes a 17 diferentes editoras, tendo constatado que, desse conjunto, 14 livros trazem, já no título, uma referência explícita aos avós, tais como, por exemplo, Vovô virou árvore, Quando vovô virou borboleta, Vovô me deu um bolo, Vovô foi viajar, As meninas, a vovó... e a saudade de quem foi pro céu. Por outro lado, episódios com personagens moribundos raramente são narrados de forma explícita nessas obras, preferindo-se o uso de eufemismos para caracterizar a morte. No livro A menina Nina, por exemplo, Ziraldo lança mão do eufemismo corrente "dormir para sempre" para se referir a "morrer": "Quando a porta do seu quarto foi aberta finalmente com força e ansiedade, lá dentro, Vovó dormia serena como viveu. Vovó dormia para sempre." (ZIRALDO, 2002, p. 27). Outros recursos frequentemente utilizados são as imagens alegóricas e o apelo ao fantástico e ao maravilhoso - principalmente o uso de animais como personagens. No livro Vovô virou árvore, para citar um exemplo, quem morre é o vovô tartaruga, que "rolou, rolou, rolou. Bateu 
a cuca nos seixos. Torceu o pescoço. Arregalou os olhos. Deu um suspiro... e morreu" (CHAMLIAM; ALEXANDRINO, 2009, s/p.).

As principais explicações formuladas, contemporaneamente, pelos autores brasileiros, para o acontecimento da morte, assemelham-se às explicações encontradas em livros estrangeiros, especialmente a ideia de que a pessoa morta não desaparece enquanto sua memória é mantida. Essa estratégia está presente, por exemplo, no livro Avôs e avós, de Nelson Albissú, em que o personagem criança pergunta, ao avô, se sua avó teria ido para o céu, recebendo a seguinte resposta: "Acho que sim. Mas não importa aonde ela foi. O importante é que ela mora no seu coração." Alguns livros brasileiros também seguem a tendência de conferir explicações secularizadas e imanentes para a morte e a finitude, como é o caso de Vovô virou árvore, de Regina Chamliam e Helena Alexandrino. Quando a personagem infantil Albertina pergunta se chegará a ver seu avô novamente, a avó responde que "o vovô será devolvido à natureza [...]. Ele será recoberto por folhas e flores, vai virar nuvem, vai virar chuva, vai virar árvore" (CHAMLIAM; ALEXANDRINO, 2009, s/p).

Por outro lado, chama a atenção o fato de que há ainda um número considerável de livros brasileiros que apostam em explicações metafísicas e de caráter religioso para a morte, apelando para o clássico consolo segundo o qual a pessoa morta estaria feliz em um outro plano de existência, geralmente descrito em termos cristãos. O livro A poltrona vazia pode ser citado como um exemplo típico quanto ao uso dessa fórmula: "[Mamãe] contou que o vovô tinha ido para o paraíso. Outra vez perguntei se, no tal paraíso, o vovô não ia se sentir sozinho longe da gente. Mas mamãe disse que ali ele encontraria as outras pessoas que ele também amava e já morreram (...)" (SARUÊ; BOFFA, 2005, p. 17). A menina e o sol é outro exemplo de livro que repete uma fórmula religiosa - esse caso, através de um diálogo em que a personagem menina procura esclarecer suas dúvidas sobre o "céu” em que a vovó estaria e o "céu” que ela vê de noite. Outro livro que lança mão de fórmulas religiosas é As meninas, $a$ vovó... e a saudade de quem foi pro céu, no qual os autores assumem explicitamente uma explicação católica para a morte, recorrendo à imagem do paraíso a ser alcançado através da ressurreição.

Realizado este rápido percurso pela presença do tema da morte na literatura infantil, voltemo-nos para o livro focalizado neste trabalho, que será discutido na próxima seção. Uma primeira diferença em relação às tendências recentes apontadas em livros com tais temáticas já está no nome da obra - a morte está presente no próprio título do livro. 


\section{O pato, a morte, a tulipa}

O pato, a morte, a tulipa é uma tradução realizada pela editora Cosac Naify, em 2009, do livro ilustrado Ente, Todund Tulpe, produzido pelo renomado artista alemão Wolf Erlbruch e publicado, originalmente, em 2007, pela editora Antje Kunstmann, de Munique. Em 2008, o livro foi condecorado com o Deutscher Jugendliteraturpreis - Prêmio Alemão de Literatura para Jovens - do qual Erlbruch já havia recebido, em 2003, um prêmio especial por sua obra completa. Outras importantes homenagens recebidas por Erlbruch incluem, também pela obra completa, o prêmio Hans Christian Andersen, em 2006, além do prêmio Bologna Ragazzi, em 2000, pelo livro Das neue ABC-Buch (O novo livro do $A B C$ ) e, em 2004, pelo livro The Big Question (A grande questão). Em 2017, Erlbruch foi o ganhador do prêmio sueco Astrid Lindgren Memorial. Do conjunto de sua produção, algumas obras estão disponíveis em português, tais como O urso que queria ser pai(Companhia das Letrinhas, 1996), A senhora Meier e o melro (Companhia das Letrinhas, 1998), Leonardo (Companhia das Letrinhas, 2004) e A grande questão (Cosac Naify, 2012). Como ilustrador, também estão disponíveis os livros $O$ rei e o mar (Companhia das Letrinhas, 2010), com texto de Heinz Janisch, A águia que não queria voar (Companhia das Letrinhas, 2012), com texto de James Aggrey, e o conhecidíssimo Da pequena toupeira que queria saber quem tinha feito cocô na cabeça dela (Companhia das Letrinhas, 1994), com texto de Werner Holzwart.

Assim que foi lançado, $O$ pato, a morte e a tulipa tornou-se um sucesso imediato não apenas no contexto da crítica especializada, mas também da mídia, tendo angariado resenhas positivas em importantes jornais alemães, como o Frankfurter Allgemeine ${ }^{2}$ e Die Zeit ${ }^{3}$, bem como em jornais igualmente importantes fora da Alemanha, como The Guardian ${ }^{4}$. Por outro lado, juntamente com os elogios, o livro desencadeou, de imediato, fortes controvérsias quanto à adequação da temática abordada em relação ao público infantil: a morte. Em 2010, Matthias Bruhn produziu um filme de animação de 11 minutos a partir do livro de Erlbruch que, em 2012, ficou entre os finalistas do Prix Jeunesse International. ${ }^{5}$ Naquela ocasião, acirrou-se ainda mais a discussão sobre a ade-

2 http://www.faz.net/aktuell/feuilleton/buecher/rezensionen/belletristik/stirbt-die-ente-stirbt-auch-der-teich-1413110.html

3 http://www.zeit.de/2007/12/KJ-Erlbruch

4 https:/www.theguardian.com/books/2009/dec/19/wolf-erlbruch-children-picturebook-review

5 A animação está disponível, com legendas em português, no seguinte endereço eletrônico: https://www.youtube.com/watch?v=CCEHLloaIPg 
quação da história ao público infantil, sendo que alguns dos críticos presentes chegaram a afirmar que a animação seria inapropriada para crianças. Uma das falas que sintetiza as críticas - disponibilizada por Palomo (2012) - é a seguinte:

Eu realmente não acredito que seja para crianças. Eu acho que foi feita para nós, adultos... poderia ser ofensiva para qualquer família com qualquer filiação religiosa, ou para qualquer pai que simplesmente gostaria de explicar, aos seus filhos, que existe outra vida, vida após a morte ou algo parecido.

Diferente dos demais livros de Wolf Erlbruch, portanto, O pato, a morte e a tulipa aborda a difícil temática da morte e, ao contrário do que geralmente predomina em livros contemporâneos para crianças sobre o tema, Erlbruch não explora a morte de um avô ou de um ancião, mas do próprio personagem principal, representado, aqui, pela figura antropomorfizada de um pato. Além disso, embora o autor utilize um animal como personagem, em sua narrativa, o uso desse recurso não produz eufemismo e tampouco o abrandamento da temática. Lennart Eng (2017), um dos jurados do Astrid Lindgren Memorial, esclarece que Erlbruch levou 10 anos para finalizar o livro, o qual pode ser interpretado como uma releitura das danses macabres medievais, cuja função, originalmente, era ajudar as pessoas a elaborarem o medo da morte face aos horrores da peste que se propagou pela Europa no final da Idade Média ${ }^{6}$.

O enredo criado por Erlbruch é aparentemente simples: um pato sente arrepios ao se dar conta de que está sendo seguido pela morte - figurativizada como um ser antropomórfico, com cabeça de caveira, vestindo uma bata xadrez e carregando uma tulipa; contudo, ao longo da trama, ambos os personagens vão desenvolvendo uma delicada relação de afeto, companheirismo e amizade, a qual se mantém até o final da história, quando o pato morre e é carregado pela morte na direção deum "grande rio", numa alusão intertextual à mitologia grega,

6 De acordo com Umberto Eco (2010, p. 67), as danças macabras surgiram no século 14, como um ritual cuja finalidade era ajudar as pessoas a elaborarem o medo da morte em face dos horrores causados pela grande peste. As representações visuais desse ritual geralmente trazem a figura de papas, monges, imperadores e jovens moças dançando junto com esqueletos, sugerindo, alegoricamente, a irrelevância das diferenças de idade, poder e riqueza frente à finitude. Na Renascença, tornaram-se populares pequenos livros ilustrados com xilogravuras da dança macabra, sendo a obra pictórica de Hans Holbein uma das mais utilizadas para as ilustrações daquele período. 
ao mito de Caronte (ou Cáron), encarregado de conduzir os recém-mortos ao Hades através do rio Aqueronte 7 .

O lirismo do texto já pode ser percebido no próprio título, cuja tradução ao português foi capaz de manter a aliteração produzida com a repetição da letra "t" em "paTo", "morTe" e "Tulipa" (presente no original alemão EnTe, Todund Tulpe), assim como a gradação vocálica descendente nos fonemas das sílabas que iniciam cada palavra, começando com a vogal aberta "a" (pAto/Ente), seguindo para uma vogal mais fechada (mOrte/TOd) e finalizando com uma vogal muito fechada (tUlipa/TUlpe). De fato, o refinamento estético de toda a obra só se revela quando se olha para os detalhes, pois há uma economia de palavras e de imagens na narrativa. Visualmente, nas ilustrações, predominam cores claras e um ambiente limpo, no qual a morte e o pato despontam em molduras sem cenário em grande parte das páginas, ou com cenários minimalistas. O próprio desenho de ambos os protagonistas é feito com poucos traços e, por isso, seus sentidos conotativos são sugeridos mais pelos movimentos realizados e pelas posições ocupadas por cada um deles nas manchas das páginas do que por figuras ou adereços. Página após página, surge uma espécie de dança graciosa entre o pato e a tulipa - outra possível alusão às danses macabres -, com aproximações e distanciamentos, inclinações e elevações, cujo clímax poderia ser o abraço que ocorre duas vezes: na primeira, o pato abraça a morte e, na segunda, a morte abraça o pato -, uma alegoria que sugere, mais do que a simples aceitação da finitude que predominava como intenção das danças macabras originais, uma relação de afeto e de carinho para com ela.

O que chama atenção de imediato, quanto às imagens, é a maneira humanizada e afetuosa como a morte foi representada: embora Erlbruch tenha mantido a imagem já estereotipada da morte como um esqueleto, ele desconstrói simultaneamente a associação com os seus significados mais comuns,ligados à angústia e ao medo, lançando mão de traços visuais discrepantes em relação a esse clichê: um olhar cândido no crânio cadavérico, uma bata xadrez como vestimenta que cobre o corpo formado por ossos, movimentos graciosos, sem falar das atitudes de ternura e carinho para com o personagem prestes a morrer. Além disso, na versão de Erlbruch, ao invés da temível foice que geralmente acompanha o esqueleto, a morte carrega uma tulipa, substituindo, dessa forma, um objeto ameaçador por um signo que alude ao belo, ao encanto e à delicadeza.

A simplicidade do enredo se revela apenas aparente frente à densidade de alguns diálogos entre a morte e o pato, bem como devido ao lirismo do texto

7 Nesse sentido, é interessante ressaltar que, na mitologia etrusca, o próprio Caronte seria "um demônio incumbido de pôr termo à vida dos moribundos e depois transportá-los para o inferno" (KURY, 2001, p. 70). 
e à elevada capacidade sugestiva das imagens, de caráter minimalista. No que diz respeito aos diálogos, o que mais surpreende é que não estão presentes as fórmulas tipicamente utilizadas para consolar crianças - e adultos - frente à perda de entes queridos, tais como "O vovô está abanando para a gente lá de cima das nuvens" (SCHNETTLER, 2007, p. 1) ou "A Tia Gertrudes continua viva dentro de nós" (SCHNETTLER, 2007, p. 1). Na narrativa de Erlbruch, simplesmente não há respostas para a questão da morte, apenas perguntas, o que pode ser verificado, por exemplo, no diálogo reproduzido abaixo, em que o pato, após especular sobre o que acontece quando a vida acaba, obtém nada mais do que um mero olhar da morte:

- Alguns patos dizem que a gente vira anjo e fica sentado olhando para a Terra lá embaixo.

- Pode ser - a morte sentou-se - afinal, asas vocês já têm.

- Alguns patos também dizem que debaixo da Terra existe um inferno onde a gente é assado, se não tiver sido um pato bom.

- Vocês patos imaginam cada coisa, mas quem sabe?

- Então você também não sabe! - grasnou o pato.

A morte apenas olhou para ele. (ERLBRUCH, 2009, s/p)

A ênfase em perguntas em detrimento de respostas, na obra, instiga uma postura reflexiva ou filosófica por parte do leitor, que é desafiado a pensar sobre a fragilidade da vida (e da própria morte), a vida como um ciclo, a experiência do morrer. Em um dos pontos altos do enredo, surge, inclusive, a questão fenomenológica acerca da relação entre a realidade em si e a realidade do modo como se apresenta para a - ou se constrói pela - percepção humana: “-Quando você estiver morto, o lago também não vai estar mais lá, pelo menos não para você./ - Tem certeza? - perguntou o pato espantado./ - Certeza absoluta - respondeu a morte." (ERLBRUCH, 2009, s.p.).

\section{O trabalho de leitura e discussão da obra com as crianças}

Já na exploração anterior à leitura da obra, ficaram muito evidentes as referências à cultura da mídia televisiva no que se refere às representações prévias que as crianças possuem sobre a morte, tanto em termos imagéticos 
quanto conceituais ${ }^{8}$. Imageticamente, foi possível constatar o predomínio da representação da morte como um esqueleto que carrega uma foice (ou outro instrumento afiado) para ceifar vidas, a qual é veiculada em muitos programas televisivos e outros produtos midiáticos de grande circulação para crianças. Como parte das atividades propostas no início da sessão, após ser apresentada a capa do livro de Erlbruche lido o seu título, uma das mediadoras fez a seguinte pergunta às crianças da Escola 2: "E será que dá pra desenhar a morte?" Instigados pela indagação, alguns alunos vieram à frente da sala e desenharam, no quadro, imagens de sua própria autoria, as quais podem ser visualizadas abaixo?:

\section{FIGURA 1 - DESENHOS DA MORTE REALIZADOS POR CRIANÇAS DATURMA2}

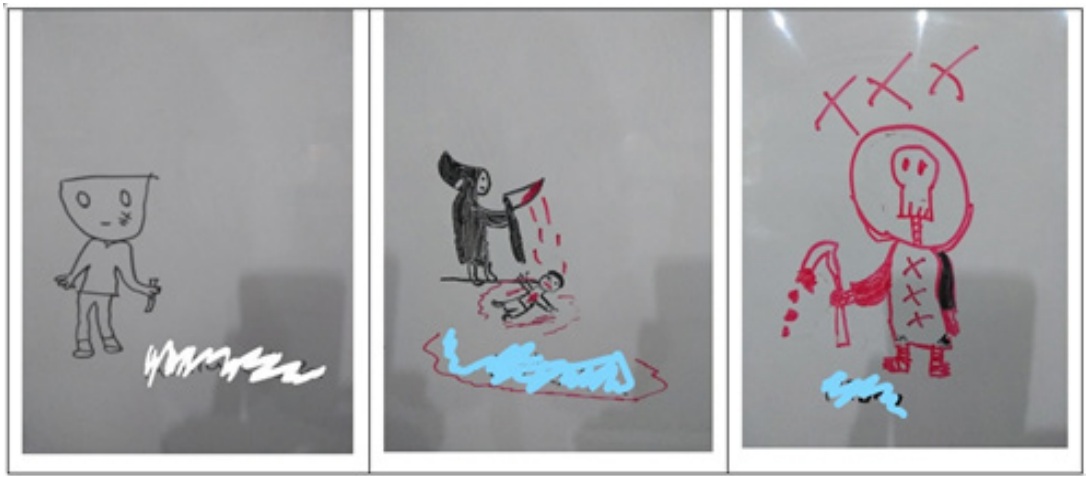

FONTE: Acervo de dados da pesquisa.

Ao explicar a origem da referência de seu desenho, o aluno A5(o), autor da imagem, afirmou ter se inspirado no filme Pânico: “A5(o): $:^{10}$ É mais ou menos o Pânico!". Na sequência dessa fala, as crianças passaram a fornecer os nomes dos principais programas midiáticos nos quais se encontram as representações

8 Brevemente, podemos caracterizar o contexto da escola 1, da rede municipal de ensino, como de um bairro conhecido na cidade de Porto Alegre por sua alta taxa de vulnerabilidade social; sua densidade demográfica é de 14.226,73 habitantes por $\mathrm{km}^{2}$, a taxa de analfabetismo é de 5,06\% e o rendimento médio dos responsáveis por domicílio é de 2,71 salários mínimos. Já a escola 2 , da rede estadual de ensino, se situa em bairro de classe média, com densidade demográfica de 6.167,98 habitantes por $\mathrm{km}^{2}$, taxa de analfabetismo de $0,78 \%$ e o rendimento médio dos responsáveis por domicílio é de 7,45 salários mínimos. Informações disponíveis em www.portoalegreemanalise. procempa.com.br.

9 Os nomes das crianças foram apagados com recursos de edição digital, de forma a preservar seu anonimato.

10 A letra A seguida de um número corresponde às vozes de diferentes alunos. As letras minúsculas (a) e (o) indicam o gênero das crianças, no caso, menina (a), menino (o). 
inspiradoras, como a animação As terriveis aventuras de Billy e Mandy, em que há um personagem chamado Puro Osso, e vários filmes de terror e suspense endereçados a adultos, tais como Sobrenatural, Anjos e Demônios, Atividade Paranormal, A invocação do Mal, Brinquedo Assassino (mencionado apenas pelo nome do protagonista, Chucky), A coisa, Sexta-Feira 13 (mencionado apenas pelo nome do protagonista, Jason), entre outros. Algumas dessas falas podem ser conferidas no excerto abaixo:

\author{
Mediadora: Vocês já viram o filme do Pânico? \\ [vários alunos juntos]: Sim! \\ Mediador: Nossa! Mas não é pra adulto esse filme? \\ A5(o): Não tenho medo mesmo! \\ A10(o): Eu vi até Sobrenatural! \\ A11(a): Anjos e Demônios... \\ A10(o): Atividade Paranormal! \\ A5(o): Eu vi A Invocação do Mal! \\ $[\ldots]$ \\ A12(a): Eu vi o It, A coisa! \\ $[\ldots]$ \\ A16(o): O Jason!
}

Os alunos da Escola 1 ainda citaram, como fonte de suas representações sobre a morte, o desenho Os Simpsons, os quadrinhos da Turma da Mônica e os "desenhos para Criança Malcriada" ". O esquema visual da morte como um esqueleto carregando uma foice ou outro instrumento cortante foi reiterado verbalmente por vários alunos de ambas as escolas. Vejamos alguns exemplos da Escola 1: "Uma caveira com um capuz e um machado na mão!" (A11); "É um facão..." (A12); "Uma foice!" (A13). Ainda antes da leitura do livro, quando foram desafiados a se expressar sobre a morte em termos mais conceituais do que visuais, por sua vez, houve o predomínio de associações entre a morte e o medo - "A16(a): Aqui no colégio, na frente dos fios, tem uma caveira ali!" -, o que pode ser explicado não apenas pelo fato de que a caveira é usada frequentemente como um signo indicial significando perigo, senão também pela referência aos filmes de terror citados acima, em muitos dos quais o protagonista é um assassino em série que mata por instinto, diversão ou psicopatia.

11 Possivelmente, o aluno estava se referindo à série de animação brasileira Historietas Assombradas (para Crianças Malcriadas), ou simplesmente Historietas Assombradas, baseada no curta-metragem homônimo criado por Victor-Hugo Borges e veiculada no Cartoon Network. 
Outras associações imagéticas e simbólicas da morte emergiram quando, ao retomarem a história lida, numa sessão posterior, os alunos da turma 2 foram questionados quanto à representação do corvo:

Mediadora 1: Será que podia ser um tucano aí? Uma pomba? Ficava bem na história?

[vários alunos juntos]: Não!

A12(o): Isso ai é de morte, sora!

A13(o): Uma pomba não tem nada a ver com uma cena de morte...

Mediadora 2: E esse bicho ai tem a ver?

[vários alunos juntos]: Tem!

Mediadora 1: Aonde que vocês já viram esse bicho?

A8(o): Nos filmes de morte sempre tem corvo...

A14(o): No filme da Malévola!

Na sequência das atividades, os mediadores leram a história para as crianças e, em seguida, estas foram provocadas a falarem sobre aquilo de que mais gostaram e do que não gostaram na obra. Nessa ocasião, as crianças trouxeram à tona novamente a associação da morte com o medo, mas também com a maldade; é interessante notar que, desta vez, elas o fizeram tomando uma certa distância em relação a essa concepção, na medida em que seus enunciados marcaram uma diferença de voz entre "nós" e "eles". Na turma 2, na fala de A39, por exemplo, o sujeito da oração é "todo mundo"; A44, por sua vez, refere-se a "ninguém", ao passo que A33 utiliza um sujeito plural indefinido e elíptico, marcado apenas pela conjugação do verbo "acham". Talvez esse distanciamento quanto à voz enunciativa possa ser interpretado como um passo na direção da desconstrução ou pelo menos do questionamento de algumas de suas convicções prévias sobre a morte.

Mediadora: Tem uma outra parte assim, que o pato pergunta pra morte: "Você está com frio? Posso te esquentar?", e aí o narrador diz: "Ninguém jamais havia feito a ela uma proposta parecida...”. Por que será que ninguém tinha feito?

A39(a): Porque ela é a morte e todo mundo acha que ela é má!

Mediadora: O que mais vocês acham?

A44(o): Porque ninguém enxerga!

A33(a): Porque acham que quando veem ela, acham que ela é muito ruim... 
A morte como uma entidade a ser temida também é referida pela última expressão exclamativa nesta sequência da conversa sobre a obra, na turma 2:

\author{
Mediadora: Como é que vocês entenderam essa parte aqui? A morte diz \\ assim pro pato: "Estou por perto desde que você nasceu, por via das \\ dúvidas". Como que a morte tá por perto desde que ele nasceu? \\ A8(o): A morte sempre tá por perto caso aconteça algum acidente ela \\ que leva o corpo... \\ Mediadora: Ela tá por perto de todas as pessoas desde que nasceu? \\ [vários alunos juntos]: Sim! \\ Mediadora: Por quê? \\ A42(a): Ela tá perto da gente agora! \\ A43(o): Tá louco!
}

Como já foi afirmado na seção anterior deste artigo, O pato, a morte e a tulipa desconstrói muitos clichês e estereótipos sobre a morte que ecoam na mídia - os quais, a julgar pelas falas das crianças destacadas nesta seção, são capazes de se instalar de forma expressiva no seu repertório cultural e cognitivo. Efetivamente, como relembra Elias (2001, p. 97), "as atitudes que hoje prevalecem em relação aos moribundos e à morte não são inalteráveis nem acidentais", sendo peculiares às sociedades desenvolvidas contemporâneas, em que "o aumento da expectativa de vida tornou a morte mais distante dos jovens e dos vivos em geral" (ELIAS, 2001, p. 97). Tal distanciamento, entretanto, é apagado na obra focalizada, e a aproximação das crianças em relação à temática parece ter tido reflexos nas suas interpretações. Assim, chamou atenção o fato de que a maioria afirmou ter gostado da relação de amizade e de afeto que se estabeleceu entre a morte e o pato, justamente o oposto do que predomina nos filmes e nas animações por eles mencionados no início da atividade. Na turma 1, causou grande surpresa, mesmo antes da leitura, o fato de que a foice fora substituída por uma tulipa na obra de Erlbruch: "Mediadora: [...] Agora vamos começar, pode abrir... Eu vou começar a ler, tá pessoal?/ A6(o): A tulipa ali ó/ A29: Tá no lugar de foice!/ A30: Na mão da caveira!". O aluno A6 enfatizou que a tulipa está no lugar da própria morte: "Eu gostei que na ilustração a tulipa tá lá naquele lugar da morte..." (A6); já o aluno A41 da Turma 2 chegou a estabelecer uma oposição entre o machado que predomina nas representações estereotipadas da morte e a tulipa na obra de Erlbruch: "O machado mata, e a tulipa, não!"

Ainda na direção do entendimento da Morte como uma personagem com sentimentos bondosos e não como uma ceifadora implacável, vale a pena citar 
a interpretação proposta por uma aluna da Turma 1, na exploração conjunta de uma passagem do texto:

Mediadora: Olha só, "quando o vento frio passou pelas suas penas, o pato sentiu um calafrio". Tem vários motivos pra ter um calafrio, um deles é febre, é doença...

A41(a): Frio!

Mediadora: E ele sentiu calafrio, talvez estivesse doente...

A4(a): Será que o pato... Será que a morte fez o pato ficar doente, pra ela não precisar ela mesma matar o pato?

Quanto à imagem da tulipa no lugar da foice, tal presença despertou a curiosidade das crianças e as desafiou a elaborar interpretações mais pessoais. Várias delas associaram, à flor, as ideias da beleza e da delicadeza, mas também de homenagem prestada aos mortos, como foi ressaltado pela aluna A31, da turma 2, conforme o excerto abaixo:

A29(a): Sora e por que que tem a tulipa?

Mediadora: Essa é uma pergunta que eu ia fazer pra vocês... O que será que significa a tulipa?

A30(a): O sora, quando ele morreu tinha uma tulipa!

A31(a): Sempre quando a gente morre coloca uma flor ou alguma coisa em cima da gente...

A32(o): No começo da história, ela tinha uma tulipa atrás, nas costas dela, e no final ela botou no ganso quando ele morreu...

Mediadora: Quem quer falar mais sobre a tulipa?

A33(a): A tulipa é uma flor muito bonita! Muito delicada...

A31(a): Essa flor é muito rara aqui no Brasil...

Outro aspecto a ser ressaltado em relação à atividade de discussão é que as crianças acabaram adentrando as questões mais filosóficas ou existenciais propostas na narrativa justamente quando se expressaram a respeito dos aspectos que não as agradaram tanto. De modo geral, a maior parte dos alunos, tanto na Turma 1 quanto na Turma 2, afirmou não ter gostado do fato de que o pato morre no final da história. Na turma 1, essa opinião foi expressa através de enunciados como "Não gostei quando o pato morreu" (A27); "Eu também!" (A5). Na turma 2, as falas foram semelhantes: "Eu gostei que ele fez amizade com a morte e não 
gostei que ele morreu" (A11); "Eu não gostei da parte que ele morreu" (A4); "Eu não gostei da parte que ele morreu também!" (A5).

Por outro lado, quando questionados sobre essa posição, vários deles acabaram tocando em questões como a morte enquanto um fenômeno inescapável e a vida como um ciclo marcado por fases. Embora expressas de forma simples, tais questões são trazidas à tona, por exemplo, pelos alunos A5, A6, A11 e A4, conforme o excerto abaixo:

A27(a): Não gostei quando o pato morreu...

A5(a): Eu também!

A6(o): É a vida, a gente nasce pra morrer...

A11(o): Ninguém pode sobreviver até mais de cem anos!

A4(a): Todo mundo morre um dia, né sora?

É importante esclarecer que, apesar das várias colaborações produtivas e pertinentes por parte das crianças durante as discussões, também houve certa dificuldade para compreender a proposta de algumas passagens da narrativa, principalmente a parte final, em que aparece, após a morte do protagonista, sem qualquer texto, um círculo formado por três personagens, sendo que dois deles não haviam feito parte do enredo até então: uma raposa, uma lebre e a morte, esta última ocupando o centro do círculo. Mesmo se defrontando com o desafio de atribuir algum sentido a essa imagem, em nenhum momento as crianças deixaram de formular hipóteses, levando ao limite sua disposição para exercitar a capacidade de interpretação, o que pode ser verificado, por exemplo, no excerto abaixo:

A39(a): Sora, por que aqui no fim tem a raposa?

Mediadora: Ótima pergunta da colega! Por que vocês acham que tem essa ilustração aqui?

A8(o): Porque significa o círculo da vida!

A47(a): Porque vai ser uma nova história!

A48(o): Porque a raposa tá atrás do coelho que mostra ali, e a morte tá esperando pra levar o coelho!

A33(a): Ela tá procurando outros animais que tem...

A10(o): Ela tá atrás de outros animais com chance de morrer...

Na turma 2, ao tentarem explicar porque a morte aparece, no final da história, junto com uma raposa e um coelho, algumas crianças ressaltaram o 
sentimento da perda, por parte da morte, em relação ao pato, aludindo à ideia de luto e, indiretamente, à amizade que havia se formado entre ambos. No excerto abaixo, os alunos A16, A5, A32 expressam essa ideia, a qual é rejeitada apenas porA6:

A16(a): Porque ela perdeu o pato e agora ela vai procurar uns amigos pra ela...

A5(a): Ela tava triste...

A32: Eu acho que ela tava se lembrando dos momentos que ela tava com ele...

A6(o): E não tava nem aí pra nada! Ela viu que a raposa ia comer a lebre e não fez nada!

Observa-se, neste diálogo, a troca produtiva de diferentes interpretações sobre as atitudes da personagem "morte". Como assevera Chambers (2007, p. 22), "el sentido de una historia para ese grupo de lectores surge de la conversación; no se establece en el inicio y luego se discute, como ocurre por lo general en una conversación académica formal sobre un libro".

Outra dificuldade de interpretação foi percebida em relação ao significado do rio ao qual o corpo do pato é levado pela morte, no final do enredo. Embora as respostas ensaiadas não tenham alcançado o simbolismo e tampouco a intertextualidade desse signo, conforme a proposta original e culturalmente informada da obra, as crianças da Turma 2 ensaiaram interpretações plausíveis, tais como as seguintes:

Mediadora: Posso fazer uma última pergunta? O que vocês acham que é o grande rio?

A10(o): É o rio da morte!

A8(o): É o mar por causa que rio não tem onda!

A49(o): É o portal da morte!

\section{Considerações finais}

Uma das principais conclusões a que as análises realizadas neste trabalho permitem chegar é de que as crianças que participaram como sujeitos desta 
pesquisa demonstraram estar fortemente capturadas por representações midiáticas sobre a morte, principalmente esquemas visuais estereotipados e conceitos que associam a morte com o medo e o mal - representações também correntes nos grupos sociais a que elas pertencem -, o que pode ser observado pelo predomínio, em suas falas e nas representações pictóricas de sua própria autoria, de referências à mídia televisiva. Por outro lado, ao longo da leitura da obra, também foram capazes de desconstruir vários elementos que compõem essas representações, principalmente a associação entre a morte e o medo. E, na sua interpretação partilhada, é importante pontuar o quanto as crianças - que crescem num ambiente povoado de imagens e telas - transitaram entre a leitura do texto verbal (inclusive perguntando à mediadora sobre uma ou outra passagem menos transparente) e a leitura das imagens, para cujos detalhes chamavam atenção e aos quais buscavam atribuir significados.

O livro de Erlbruch pode ser considerado um contraponto em relação às representações estereotipadas da morte que são colocadas para circular em meios de comunicação de massa endereçados a crianças, proporcionando a possibilidade de desconstruir clichês e estereótipos construídos visualmente para fazer circular a ideia da morte como algo macabro e aterrador. Também em relação a grande parte dos livros infantis, a obra de Erlbruch se caracteriza como um contraponto, na medida em que não fornece consolos e tampouco explicações religiosas, instigando o leitor a refletir e a chegar a suas próprias conclusões. A abordagem do autor - colocando a própria palavra "morte" no título, transformando-a em personagem e representando-a visualmente como uma espécie de caveira/esqueleto com uma túnica sóbria - rompe com o universo de eufemismos e estratégias de dissimulação que predominam nos livros sobre o tema para crianças, sem, entretanto, gerar o distanciamento do leitor, mas, ao contrário, convidando-o a partilhar de uma certa humanização da própria morte.

Neste sentido, podemos refletir sobre as palavras de Díaz (1996). Após afirmar que, na literatura para crianças, até algum tempo atrás, era difícil encontrar textos que abordassem "com naturalidade essa problemática", conclui que:

Ler sobre a morte é vivê-la por antecipação. É crescer um pouco mais internamente para estar preparado para sua vinda. Mas também é o espaço para confrontar nossas próprias experiências e descobrir nas personagens da ficção que nossas emoções, nossos sentimentos ante este fato, são também os das outras pessoas. (DÍAZ, 1996, p. 9) 


\section{REFERÊNCIAS}

CHAMBERS, Aidan. Dime - los niños, la lectura y la conversación. Mexico: Fondo de Cultura Económica, 2007.

CHAMBERS, Aidan. Conversaciones. Escritos sobre la literatura y los ninos. Mexico: Fondo de Cultura Económica, 2008.

CHAMLIAM, Regina; ALEXANDRINO, Helena. Vovô virou árvore. São Paulo: Edições SM, 2009.

COLOMER, Teresa. A formação do leitor literário. São Paulo: Global, 2003.

DÍAZ, Fanuel Hanán. Variações sobre o tratamento dado ao tema morte na literatura infantil. Revista Latino-Americana de Literatura Infantil e Juvenil. Bogotá, n. 4, p. 2-11, jul.-dez. 1996.

ECO, Umberto. Die Geschichte der Hässlichkeit. München: Deutscher Taschenbuch Verlag, 2010.

ELIAS, Norbert. A solidão dos moribundos. Rio de Janeiro: Jorge Zahar, 2001.

ENG, Lennart. Reading guide to Wolf Erlbruch's Duck, Death and the Tulip. 2017. Disponível em: <http://www.alma.se/Documents/2017/Duck,\%20Death\%20and\%20 Tulip,\%20eng.pdf $>$ Acesso em 14 de agosto de 2018 .

ERLBRUCH, Wolf. O Pato, a morte e a tulipa. São Paulo: Cosac Naify, 2009.

HESSE, M. A. Katrin. Die Darstellung von Tod und Trauer im deutschsprachigen und schwedischen Bilderbuch [A representação da morte e do luto no livro ilustrado alemão e sueco]. 2015. Tese (Doutorado) - Humboldt-Universität, Berlim, 2015. Disponível em: <https://edoc.hu-berlin.de/bitstream/handle/18452/19278/hesse.pdf? sequence=3>. Acesso em: 14 ago. 2018.

KURY, Mário da Gama. Dicionário de Mitologia Grega e Romana. Rio de Janeiro: Jorge Zahar, 2001.

PALOMO, Karen. Duck, Death and the Tulip. Prix Jeunesse International 2012. Disponível em: <http://www.br-online.de/jugend/izi/deutsch/forschung/Expertendiskussionen/7-11_Fiction/Duck_Death_and_the_Tulip.pdf>. Acesso em: 14 ago. 2018.

REINHARDT, Jan D.; WEBER, Simone. Die Todes- und Sterbethematik in Kinderbilderbüchern für die Altersklassebis 5 Jahre. Psychologie und Gesellschaftskritik, n. 32, 2008, p. 55-77. Disponível em:<http://nbn-resolving.de/urn:nbn:de:0168-ssoar-325719>. Acesso em: 14 ago. 2018.

ROSOFF, Meg. Duck, Death and the Tulip by Wolf Erlbruch. The Guardian, 19/12/2009. Disponível em: <https:/www.theguardian.com/books/2009/dec/19/wolf-erlbruch-children-picturebook-review>. Acesso em: 14 ago. 2018. 
SARUÊ, Sandra; BOFFA, Marcelo. A poltrona vazia. São Paulo: Melhoramentos, 2005.

SCHNETTLER, Silke. Stirbt die Ente, stirbtauch der Teich [Se morre o pato, também morre o lago]. Frankfurter Allgemeine, 21/03/2007. Disponível em: <http://www.faz. net/aktuell/feuilleton/buecher/rezensionen/belletristik/stirbt-die-ente-stirbt-auch-der-teich-1413110.html>. Acesso em: 14 ago. 2018.

SILVEIRA, Rosa Hessel; DALLA ZEN, Maria Isabel. Velhice e morte na literatura para crianças: apontamentos sobre o que e como se ensina a elas. In: PAES, Maria Helena Rodrigues; SILVEIRA, Rosa Hessel (Orgs.). Contribuições para o trabalho e formação docente: temas contemporâneos e sala de aula. Curitiba: CRV, 2013, p. 143-160.

ZIRALDO. Menina Nina: duas razões para não chorar. São Paulo: Melhoramentos, 2002.

Texto recebido em 08 de junho de 2018. Texto aprovado em 08 de agosto de 2018. 